\title{
Investigation of HEPA Filters Subjected to Tornado Pressure Pulses Initial Structural Testing
}


LA-7202-MS

Informal Report

Special Distribution

\section{Investigation of HEPA Filters Subjected to \\ Tornado Pressure Pulses \\ Initial Siructural Testing}

\author{
W. S. Gregory \\ H. L. Horak \\ P. R. Smith* \\ C. I. Ricketts* \\ W. Gill**
}

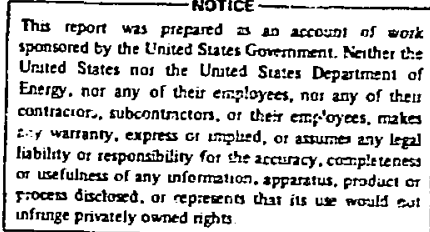

\footnotetext{
"New Mexico State University, Department of Mechanical Engineering, P. O. Box 3450, University Park, NM 88003.

**8101 Hendricks NE, Apt. 107, Albuquerque, NM 87109.
} 
INVESTIGATION OF HEPA FILTERS SUBJECTED

TO TORNADO PRESSURE PULSES

Initial Structural Testing

by

W. S. Gregory, H. L. Horak, P. R. Smith, C. I. Ricketts, and W. Gill

\section{ABSTRACT}

Initial results from a program to determine response of 610- $\times$ 610-Im (24- $\times$ 24-jn.) HEPA filters to tornado-induced pressure transients are desiribed. Filters were structurally tested by subjecting then to $20.7-\mathrm{kPa}$ (3-psi) pressure differentials at pressurization rates from $6.9 \mathrm{kPa} / \mathrm{s}(1 \mathrm{psi} / \mathrm{s})$ to $34.5 \mathrm{kPa} / \mathrm{s}(5 \mathrm{psi} / \mathrm{s})$. Two sizes of filters were used in the tests: $149 \mathrm{~mm}(57 / 8 \mathrm{in.})$ thick and $292 \mathrm{~mm}(111 / 2 \mathrm{in.)}$ thick. The 149-mu( $57 / 8$ in. -$)$ thick filters failed catastrophically at $20.7-\mathrm{kPa}$ (3-psi) pressure differentials. Pressure drop across the filters, not pressurization rate, appears to be the primary cause of failure. The 292-mm(11 $1 / 2$-in.) thick filters were also tested with the above pressurization rates. These units failed by breakage of the folded downstream ends of the fiber mat. Of four 292-mm(11 1/2-in.-) thick filters tested, a $20.7-\mathrm{kPa}$ (3-psi) pressure differential produced failure at the lowest and highest pressurization rates, but not at two intermediate rates. Additional tests will be required to determine a possible relationship between structural failure and pressurization rate.

Flow-resistance data were also obtained for the 610- $\times$ 610-min (24- $\times$ 24-in.) filters. At xelatively low flow rates, the dominant mechanism causing resistance appears to be diffusion, while at higher flow rates momentum exchange appears to dominate. At higher flow rates, probably a majority of the flow is passing through the folded ends of the fiber mat, thereby suggesting that instantaneous filtering efïiciency may be degraded.

Othe $x$ activities described concern construction of small-scale partictiate-loading and pressure-testing devices. These devices will be used to test 203- $\times$ 203-mm (8- $x$ 8-in.) filters so that methods of testing and instrumentation requirenents can be established for the fullscale tests. Progress is also reforted on the data acquisition systems, the laser instrumentation system, and the construction of a building over the facility test section.

\section{INTRODUCTION}

An experimental program to test ventilation system components is in progress at the Los Alamos Scientific Laboratory (LASL) and New Mexico State Uni- versity (MASU). I He are examining critical nuclear facility air cleaning components for their response to simulated pressure loadings as defined by the 
Nuclear Regulatory Commission (NRC) Region I tornado. ${ }^{2}$ We are testin $\mathbf{\ell}^{\prime}$ high efficjency particulate air (HEPA) filters at our test facility, which is located at MSU. These initial tests include filter structural analysis and determination of filter flow-resistance profiles. In addition, we are constructing the peripheral equipment needed in later testing phases and investigating techniques of aerosol generation and detection.

The initial structural tests involved exposure of clean 610- $x$ 610-mm (24- $x$ 24-in.) rilters, Size $A$ and Size $B$, * to a simulation of the NRC Region I tornado. The Region I tornado definition specifies a particular rate and magnitude of depressurization expected from this class of tornads However, experimental apparatus that produces a pressuitization pulse is more conveniant to build. Since the important parameter is differential pressure across a component, the test effect is similar. Our interpretation of the Region I tornado resulted in the test overpressure pulse represented by Fig. 1. We also examined the effect of increasing pressurization rate from the specified $6.9 \mathrm{kPa} / \mathrm{s}$ (1 psi/s) to $41.4 \mathrm{kPa} / \mathrm{s}$ (6 $\mathrm{psi} / \mathrm{s}$ ) while holding the maximum pressure at $20.7 \mathrm{kPa}$ (3 psi).

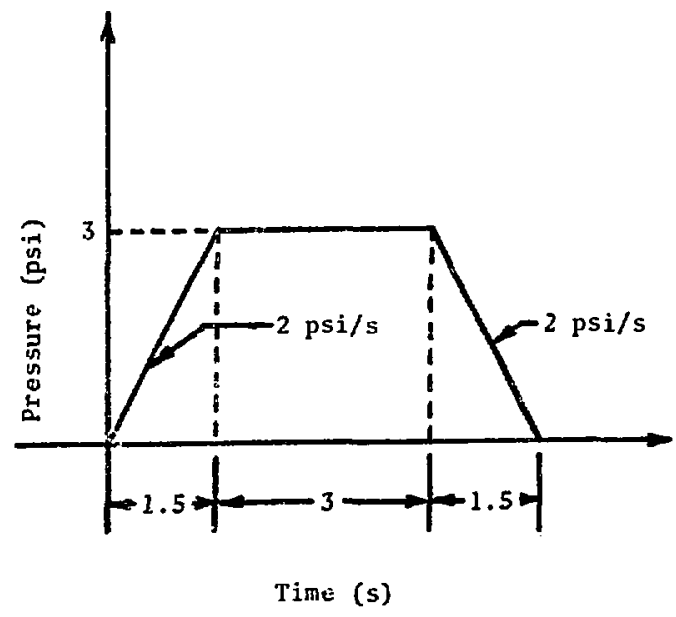

Fig. 1. Region I tornado transient.

\footnotetext{
*Filters: Size A--610 x $610 \times 292 \mathrm{~mm}(24 \times 24 \times$ $111 / 2$ in.).

Size B $-.610 \times 610 \times 149 \mathrm{~mm}(24 \times 24 \times$ $57 / 8$ in.).
}

The flow-resistance tests were perforred for the Size $A$ and $B$ filters. Curves relating air flow and resistance were generated by ceasuring velocity and filter pressure drop (AP) for several air supply pressures.

\section{FILTER RESISTANCE}

Empirical flow-resistance data are used in the computer simulation of ventilation $s y=t e n$ response to tornado-induced transients. Data are needed to define the mathematical relationship between flow through, resistance of, and pressure drop across filters at high flow rates. Further, examination of the relationship obtained will provide insight intc the filtering behavior of HEPA. filters at high fow rates.

The pressure drops across both Size $A$ and Size $B$ HEPA filters were measured at flow rates from just above their design flow rates of $0.519 \mathrm{~m}^{3} / \mathrm{s}(1100 \mathrm{cfm})$ and $0.236 \mathrm{~m}^{3} / \mathrm{s}$ (500 cím), respectively, up to nearly $11.328 \mathrm{~m}^{3} / \mathrm{s}(24000 \mathrm{cfm})$. Figure 2 shows the pressure in inches of water as a function oj +low rate. The Size B filters offer more flo: =sistance than the Size A filters.

Table A-I (Appendix) shows the test parameter values and filter resistance coefficients $\left(K_{L}, K_{T}\right)$ for different storage tank pressures. The filter resistance calı be characterized as a diffusion process or as a momentum exchange. If the process is entirely diffusion, then the pressure rise will be a function of velocity,

$$
\Delta \mathrm{P}=K_{L} \frac{k \cdot V}{D},
$$

where $\mu$ is the dynamic viscosity, $v$ is the velocity, $K_{L}$ is a resistance coefficient, and $D$ is a characteristic length. This process should occur if the Reynolds number, based upon filter fiber dianeter, is on the order of unity. If the frocess is entire? $y$ momentum exchange, then the pressure rise across the filter shouid be

$$
\Delta P=K_{T} \frac{\rho v^{2}}{2 g},
$$

in which $\rho$ is the density of the air, $g$ is the gravitational constant, and $x_{T}$ is a resistarce coefficlent . 


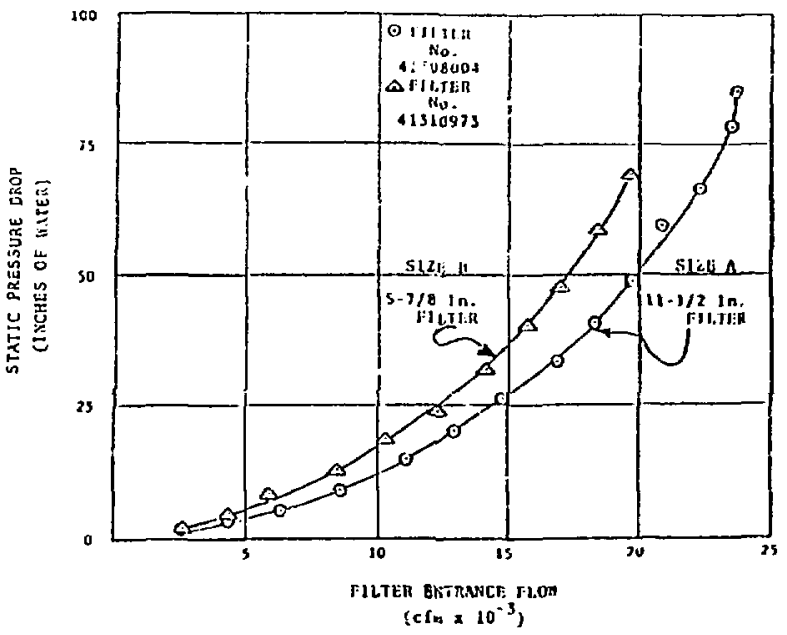

Fig. 2. Resistance of Size $A$ and Size $B$ HEPA filters at high flow rates.

Although both diffusion and momentum exchange are occurring at all flow rates, apparently at the low flow rates the diffusion process is dominant, while at high flow rates momentum exchange dominates. is can be seen from Eqs. (1) and (2), a constant value of $K_{L}$ would result if the former were true, and a constant value of $K_{T}$ would iesult if the latter were true. Examination of Table A-l reveals that at flow rates below $5.19 \mathrm{~m}^{3} / \mathrm{s}$ ( $11000 \mathrm{cfm}$ ), $K_{L}$ is essentially constant for each filter tested. For example, consider filter No. 41310856 , a Size A filter. For flow rates from $1.779 \mathrm{~m}^{3} / \mathrm{s}(3770 \mathrm{cfm})$ to $5.391 \mathrm{~m}^{3} / \mathrm{s}$ (11 $421 \mathrm{cfin}$ ), the value of $\mathrm{K}_{\mathrm{L}} \times 10^{-6}$ varies from 4.1 to 7.5 with a mean value of 6.61 and a standard deviation of 1.49. Filter No. 41310972, a Size B filter, had a range of $K_{L} \times 10^{-6}$ from 8.3 to 11.4 with a mean value of 10.13 and standard deviation of 0.95. In the latter case, flow rates varied from $1.770 \mathrm{~m}^{3} / \mathrm{s}(3749 \mathrm{cfm})$ to $5.465 \mathrm{~m}^{3} / \mathrm{s}$ (11 $579 \mathrm{cfm}$ ). These results were typical the Size $B$ filters having a more nearly constant value of $K_{L}$ at low flow rates than the Size A filters. The Reynolds rumber, based upon an average fiber diameter of $5 \mathrm{~lm}$, ranged from 3 to 9. Hence, we would expect the diffusion law to hold. Notice that for luw flow rates the value of $k_{r}$ varies as much as $200 \%$, for example, from 26.7 to 46.2 for filter No. 41310856 (Size A) and from 39.2 to 92.3 for filter No. 4130972 (Size B). From this we conclude that from $1.770 \mathrm{~m}^{3} / \mathrm{s}(3749 \mathrm{cfm})$ to about $5.19 \mathrm{~m}^{3} / \mathrm{s}(11000 \mathrm{cim})$ the diffusion process is dominant.
Fros about $6.136 \mathrm{~m}^{3} / \mathrm{s}$ (13 000 $\mathrm{cfc}$ ) to $11.092 \mathrm{~g}^{3} / \mathrm{s}$ (23 $500 \mathrm{cfi})$, the value of $x_{\mathrm{T}}$ renains resarkably constant. For filter No. 41310856, a Size A filter, $\mathrm{K}_{\mathrm{T}}$ varies from 25.9 to 29.0 with a mean value of 27.25 and a standard deviation of 0.90 . For filter to. 4130972 , a Size B filter, $K_{T}$ varies frou 35.1 to 36.3 with a mean value of 35.68 and a standard deviation of 0.59 . Thus, for flow rates above $6.136 \mathrm{a}^{3} / \mathrm{s}$ (13000 cfm), the filters behave as if moisentus exchange is the main cause for pressure loss. Notice that this flow rate of $6.136 \mathrm{~m}^{3} / \mathrm{s}$ (13 ofo $\mathrm{cfD}$ ) occurs at a pressure differential of $6.9 \mathrm{kpa}$ ( 1 psi) or less. So, for the Region I tornado for which the pressure drop is $20.7 \mathrm{kPa}$ ( $3 \mathrm{psi}$ ), the flow through the filters should exhibit resistance to flow proportional to the velocity squared (Eq. 2).

During the resistance testing, all the Size $B$

filters failed either vy sustaining tears in the folds or by blowing out completely before a $20.7-\mathrm{kPa}(3-\mathrm{psi})$ pressure difference across the filter was obtained. Filter No. 41310856, a Size $A$ filter, failed with a rip in one fold at a pressure difference of $20.4 \mathrm{kPa}$ (2.95 psi). Filter No. $4 i 308004$, also a Size A filter, did not visibly fail.

\section{III . PRELIMINARY STRUCTURAL TESTING}

Three modes of fiiter failure are being investigated. First, we are considering structural failure. In this case the filter media may be physically damaged. Preliminary test results vere obtained and are described in this report. The two other failure modes, which could occur without structural failure, address the loss of filtration capability during the tornado pulse. These failure modes are the reintrainment of particies from the filter media and the passing of particles entrained in the flow. These modes of failure will be considered in subsequent phases of the investigation.

The Size $A$ and Size B HEPA filters were subjected to 20.7-kPa (3-psi) pressure differentials at various pressurization rates. Nominally, these pressurization rates were to be $6.9 \mathrm{kPa} / \mathrm{s}$ ( $2 \mathrm{psi} / \mathrm{s}$ ), $13.8 \mathrm{kPa} / \mathrm{s}$ ( $2 \mathrm{psi} / \mathrm{s}), 27.6 \mathrm{kPa} / \mathrm{s}$ ( $4 \mathrm{psi} / \mathrm{s}$ ), and $34.5 \mathrm{kPa} / \mathrm{s}$ ( $5 \mathrm{psi} / \mathrm{s}$ ). However, because of the itpedance of the flow systen, these pressurization rates could only be approxinated. Table 1 contains the pressurization rates applied to each filter. 
SABLE I

STRUCTURAL TEST PRESSURIZATION RATES \& RESULTS

\begin{tabular}{|c|c|c|c|c|}
\hline Filear size & Presplu: & ion Race & $\begin{array}{c}\text { Frontal } \\
\text { Area } \\
\text { Descroyed } \\
(3) \\
\end{array}$ & $\begin{array}{l}\text { Dop } \\
\underline{(z)} \\
\end{array}$ \\
\hline $\boldsymbol{A}$ & 6.62 & 0.96 & 0.69 & 1 \\
\hline$A$ & 12.76 & 1.85 & 0.00 & 0.002 \\
\hline $\boldsymbol{A}$ & 24.63 & 3.97 & 0.00 & 0.001 \\
\hline$A$ & 31.40 & 4.55 & 1.64 & 6 \\
\hline $\mathbf{B}$ & 3.66 & $1.1 t$ & 100 & 100 \\
\hline$B$ & 13.25 & $\therefore .92$ & 100 & 100 \\
\hline B & 31.40 & $\div .55$ & 100 & 100 \\
\hline B & 34.50 & 5.00 & 100 & 100 \\
\hline
\end{tabular}

The objective of these tests was to determine if the structural integrity and the efficiency of the filters were affected by the rate of pressurization. Each filter tested was subjected to only one pressure pulse. Efficiency tests were performed at Department of Energy quality assurance stationz before the filters were shipped to NMSU. Afier each filter was puised, its efficiency was again measured using the standard dioctyiphthalate (DOP) method.

Figures 3 and 4 show the pressure rise across the filters as a function of time for Size $A$ and Size B filters, respectively. Notice that in all cases the maximum pressure drop across the filters, called static pressure in the figures, was within $0.69 \mathrm{kPa}(0.1 \mathrm{psi})$ of $20.7 \mathrm{kPa}$ (3 psi) .
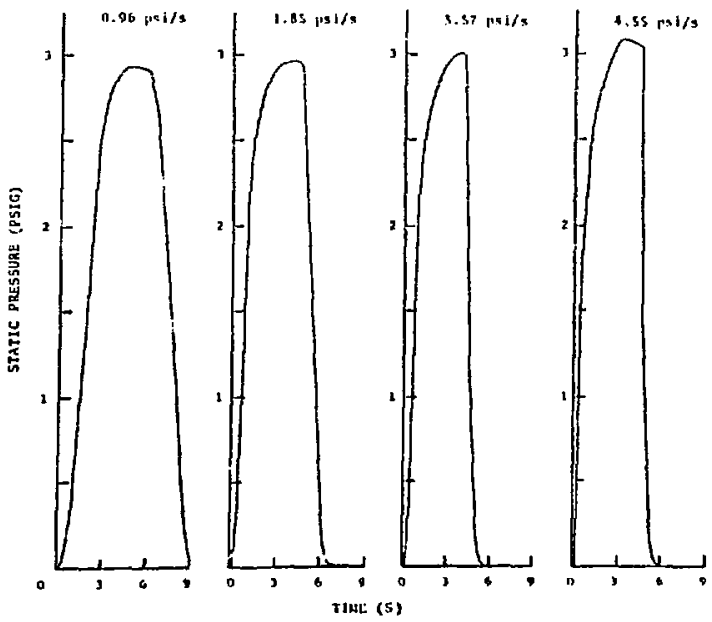

Fig. 3. Pressure drop across Size A HEPA filters during structural tests.
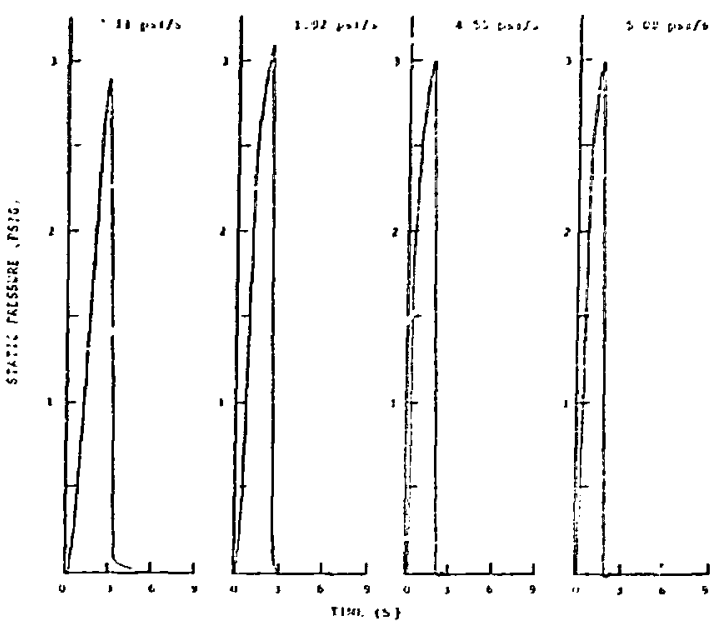

Fig. 4. Pressure drop across Size B HEPA filters during structural tests.

For the Size A filters, failures occurred at pressurization rates of $6.62 \mathrm{kPa} / \mathrm{s}(0.96 \mathrm{psi} / \mathrm{s})$ and $31.40 \mathrm{kPa} / \mathrm{s}(4.55 \mathrm{psi} / \mathrm{s})$. The failure mode in both cases was a ripping out of a very smail percentage of the folded ends on the dounstream face of the fiitcr as can be seen ifi Figs. 5 and 6 . In the lon-

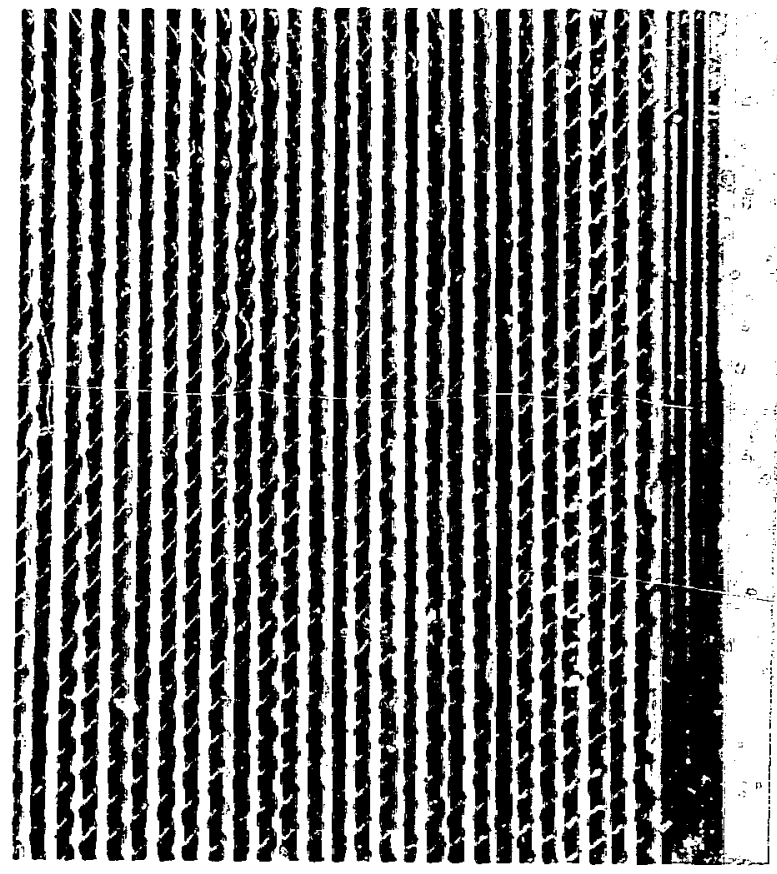

Fig. 5. Failure of Size A HEPA filter subjected to $6.62-\mathrm{kPa} / \mathrm{s}(0.96-\mathrm{psi} / \mathrm{s})$ pressure drop. Sinall tears visible against right-hand woll (Filter No. 41310371). 


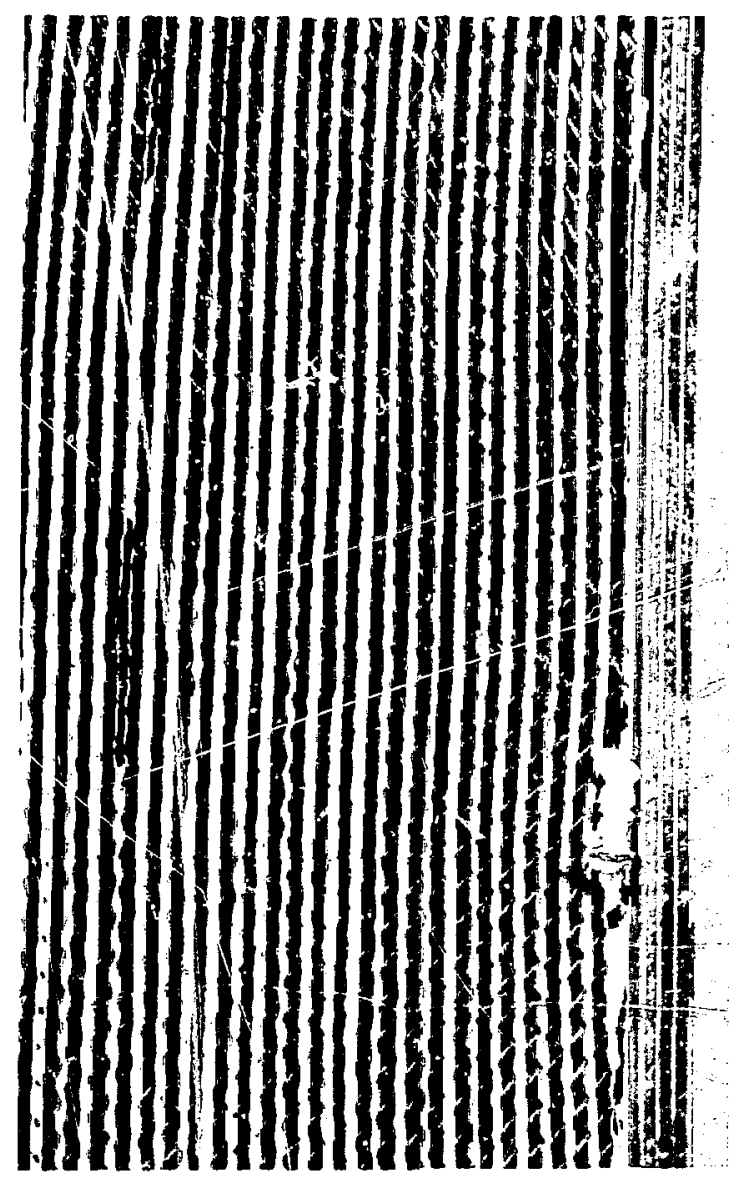

Fig. 6. Failur $\Leftrightarrow$ of Size A HEPA filter subjected to $30.4-\mathrm{k}$ 'a/s (4.55-psi/s) pressure drop (Filte' No. 41.30365).

pressurization case, $0.69 \%$ of the filter frontal area failed, wh: le in the high-pressurization case, $1.64 \%$ of the toral filter frontal area failed. The two filters sub: ected to the intermediate pressurization rates showed no visible signs of structural damage.

After testing, the filter efficiency of the four Size A filters was determined using standard DOP teciniques. These results are shown in Table $f$. Filter No. 4131(37) was subjected to a pressurization rate of $6.1 .2 \mathrm{kPa} / \mathrm{s}(0.96 \mathrm{psi} / \mathrm{s})$, sustained a sme11 amount of damage, and had a maximum DoP reading; of 1s. Filter 1:o. 413036j, which was subjected to a pressurization rate of $31.40 \mathrm{kPa} / \mathrm{s}(4.55 \mathrm{psi} / \mathrm{s})$ and also received damage, had a maximum Dop reading of 6\%. The other wo Size A filters (Nos. 41310842 and 41310843) had DifP readings of $0.00 \%$ and $0.001 \%$, respectiveiy.
All Four of the Size B filtars subjected to the $20.7 \mathrm{kPa}$ (3 psi) pressure fulse at the varius pressurization rates failed catastrophically. In each case, the filter was blown out of the filter frace, as can be sein in Fig. 7. We conclusie that the naximum pressure, not the rate of pressurization, caused the failure of these filters. Since thw entire filter tore out of its frame, a probable fillure mode is shearing of the paper at the perimeter where it is glued to the frame. Further, since the Size A filters failed by breakage of a small percentage of the downstrean folds, at least two failure modes exist. Because the Size B filters failed completely, their filter efficiency after testing was zero.

IV. DISCUSSION OF EXPERIMENTAL RESULTS

A. Resistance Measurements

The results of the resistance measurements on the Size A and Size B HEPA filters appear to agree with the results folnd earlier for the $203-\times 203-m$ ( 8 - $\times 8$-in.) filters. ${ }^{3}$ At low flow rates, the dorinent mechanism causing resistance appears to be diffusion, while at the higher flow rates momentur

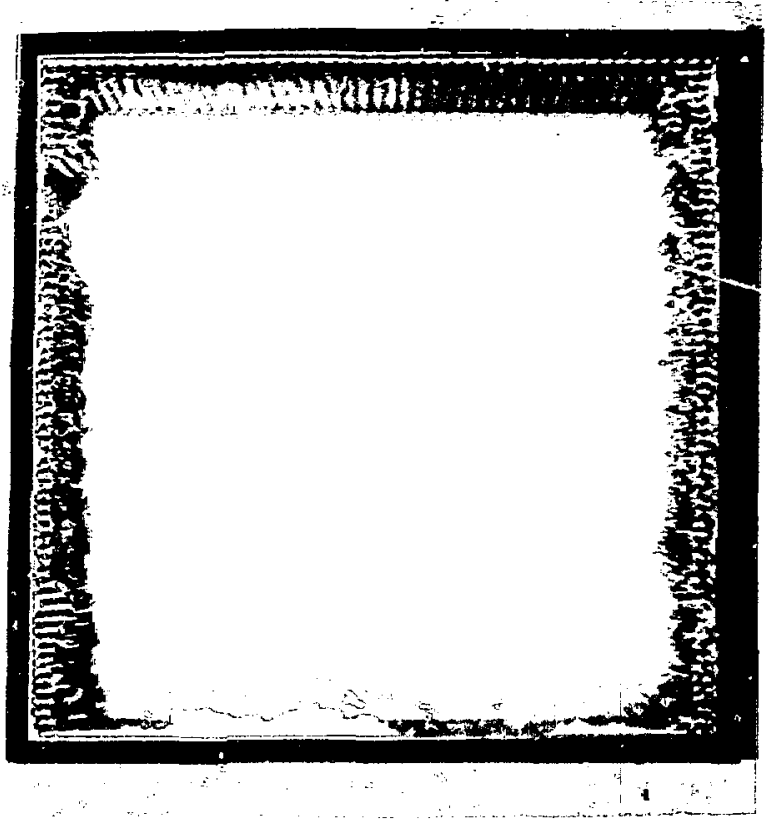

Fig. 7. Typical Size B HEPA filter after presiarization to $20.7 \mathrm{kPa}$ ( $3 \mathrm{psi}$ ) at rates varying from $7.5 \mathrm{kP} / \mathrm{s}(1.1 \mathrm{psi} / \mathrm{s})$ to $34.5 \mathrm{kPa} / \mathrm{s}$ (5 psiis). 
exchange dominates. The latter situation exists when the pressure drop across the filter is approximately $0.9 \mathrm{kPa}$ ( 1 psi) or greater. For flows in which momentum exchange is the chief mechanism of resistance, a majority of the flow probably is passing through the fold $\mathrm{xl}$ ends of the filter paper and thus instantaneous filtering efficiency may be degraded. Such an occurrence could not be detected by a DOP test made after the fact.

B. Structura1 Test

Size B HEPA filters subjected to a 20.7-kPa (3-psi) pressure differentia? at pressurization rates of $6.9 \mathrm{kPa} / \mathrm{s}(1 \mathrm{psi} / \mathrm{s})$ to $34.5 \mathrm{kPa} / \mathrm{s}(5 \mathrm{psi} / \mathrm{s}$ ) failed catastrophically. The pressure rise across the filters, not the pressurization rate, appears to be the primary cause for isur failure. These filters could not withstand a NRC Region I tornado. Since the entire filter is ripped from its frame, one failure mode may be shearing of the filter paper at the perimeter. Another possible failure mode is that of plate-like deflection of the center of the filter and a failure when the effective ultimate strength of the material is surpassed.

The Size A HEPA filters failed by breakage of the folded ends of paper. A 20.7-kPa (3-psi) pressure drop across these filters caused failure at the lowest and highest pressurization rates, but not at the two intermediate rates. The two filters that failed subsequent1y showed large DOP percentages, indicating a failure in ability to filter. However, the two filtars that did not fail had Dop percentages within acceptable limits, and tnerefore no degradation of efficiency occurred. Thus, the Size $A$ fiiters appeared to fail randomly when subjected to a 20.7-kPa (3-psi) pressure differential. Within the Iimits of the pressurization rates used, this parameter may or may not have caused failure. Notice that a larger area of filter breakage occurred for the high pressurization rate. On the other hand, if failure occurs randomly because of filter fabrication differences, then pressurization rate may not be important for this pressure difference. The four tests so far performed are not a large enough sample to get statistically meaningful results.

Whatever the cause, the Size A filters do fail. Since the folded ends of these filters break out in a smail area of the filter compared to the $100 \%$ failure of the Size $B$ filters, at least two modes of failure probably exist. For the Size A filters, the folded ends may be stretched wuch like the skin of a balloon is stretched as it is inflared. Failure occurs when the tensile stress in the paper exceeds its ultimate strength.

\section{v. PäRlLLEL ACTIVITIES}

A. Velocity Profiles

Velocity profiles in the test duct were determined using the cruciform. stagnation rake shown in Fig. 8. Static pressure was measured at a wall tap at the same location. The profiles were measured at eight different fiow rates for pressure drops across a Size A filter ranging from $6.56 \mathrm{kPa}$ (0.95 psi) to $22.08 \mathrm{kPa}(3.2 \mathrm{psi})$.

Figure 3 sticws a summary of the vertical and horizontal velocity profile data. Velocity divided by the maximum (center line of duct) velocity is plotted as a function of the nondimensjoral juct coordinate. The maximum standard deviation for any of the experimental points plotted in this figure tias 0.03 .

Notice that the vertical profile is essentially symmetric, but horizontal profile displays a very slight asymmetry. At the maximum, the deviation from a symmetric profile is $5 \%$ and is within the expected experimental error.

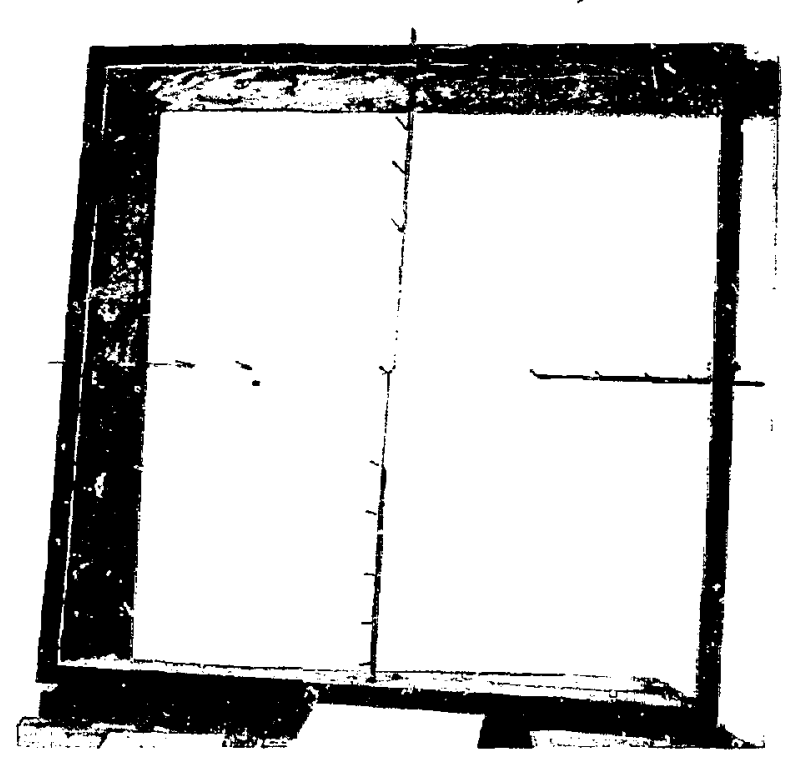

Fig. 8. Cruciform stagnation rake. 


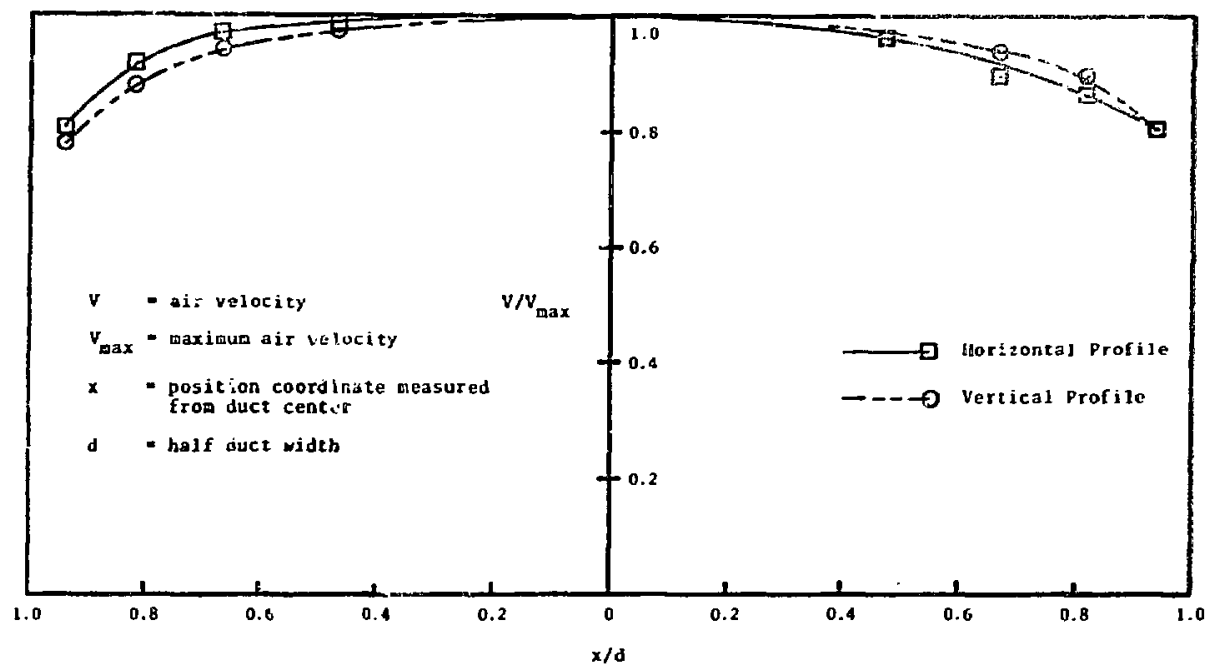

Fig. 9. Vertical and horizontal velocity profiles $i-{ }^{-}$the test duct.

B. Small-Scale Particulate Loading Device

The small-scale loading device was desigited to load 203- $x$ 203-mm (3- $\times$ 8-in.) filters with farticulate and also to expose these filters to several levels of humidity before subjecting them to pressurization. In addition, this apparatus can be used for testing filter effectiveness using DPP = Buth the small-scale loading and testing devices will be used to establish methods of testing, instrumentation requirements, and test procedures before attempting to test Size A and Size B HEPA filters.

A schematic of the device is shown in Fig. 10 . It is a positive pressure system with air entering at the fan and exiting downstream of the test filter. The fan is capable of $1.135 \mathrm{~m}^{3} / \mathrm{s}(2400 \mathrm{cfm})$ at $1619-\mathrm{kPa}$ (6.5 in. of water) total pressure. There is

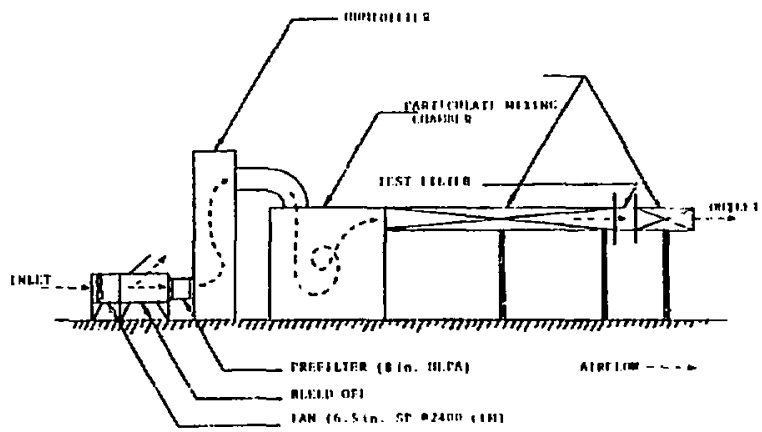

Fig. 10. Small-scale particulate HEPA filter loading device. a bleed-off damper te reduce the flow to $0.024 \mathrm{~m}^{3} / \mathrm{s}$ $(50 \mathrm{cfm})$ at the test filter. A single $0.024-\mathrm{m}^{3} / \mathrm{s}$ (50-cfm) HEPA filter prefilters the air just after the damper and before entering the humidifier.

The humidifier is an evaporative cooler that uses a counterf low air-water system through $0.057 \mathrm{~s}^{3}$ $\left(2 \mathrm{ft}^{3}\right.$ ) of cooler pads. The air is ducted from the top of the humidifier into a 1.2- $\times 1.2-\mathrm{m}$ (48- $x$ 48-in.) mixing chamber. Here, the loading particulate is introduced ind allowed to thoroughly mix with the air before exiting into a duct section that leads to the test filter. This duct is of sufficient length for the air to achieve uniford flow before impinging upon the test filter. The flow finally exits through another $0.61-\mathrm{m}$ (2-ft) length of di:ct. The system has multiple taps for pressure neasurement, and the duct upstream and downstream from the filter is modified for DOP testing.

Calibration tests to establish humidity and flow values have been completed using the device. At $0.024 \mathrm{~m} / \mathrm{s}(50 \mathrm{cfm})$, a $50 \%$ rise in relative humidity is possible when the ambient humidity is 20\%. Significant pressure drops across test filters have not been noted for continuous operation up to $\boldsymbol{E}$ h.

c. Smal1-Scale Testing Devices

A small-scale testing device that was used to appl) pulsed pressure loadings on 203- $\times$ 203(8- $x$ 8-in.) filters in an earlier investigation is being rebuilt. ${ }^{3}$ Rebuilding this apparatus will 
allow investigation of potential problems and techniques on a much smaller scale before these techniques are applied to the full-scale facility. Further, the quantity of aerosol needed for this device is several times smaller than that required for testing the 610- $\times$ 610-mm (24- $\times$ 24-in.) filters. The data acquisition and laser instrumentation systems will be evaluated with this device before installation at the 610- $x$ 610-mm (24- $x$ 24-in.) testing facility.

D. Data Acquisition System

All parts for the data acquisition system have been received and fabrication has begun. Wiring of the system is $75^{\circ}$ completed. All prebuilt componnerits such as the tape recorder and video terminal have been tested and integrated into the system. Sof tware progranming has begun and should be completed. Final check-out of the system is anticipated by July 31, 1977.

E. Laser Instrumentation System

The second laser was received after a 4-month delay. A surplus lathe bed has been located and will serve as a mobile base for mounting the lasers and associated optics. Some initial calculations were made to establish the laser measuring volume size assuming a 400-mm focal length and a $50.8-\mathrm{mm}$ focusing lens diameter. These calculations were necessary to establish preliminary particle generation requirements.

\section{F. Building}

NMSU is constructing a building around part of the existing large-scale testing facility. The dimensions of the bliilding are $12.2 \times 12.2 \times 30.5 \mathrm{~m}$ ( $40 \times 40 \times 10 \mathrm{ft}$ ), and it is constructed of metal on a concrete slab floor. It will enclose the valves, prefilter chamber, and duct test section and will provide additional work space. The building will also serve as part of a shield for the laser instrumentation, thereby reducing exiraneous scattered iight and particulates in the air.

\section{i'I. SUMMARY}

The initial structural test results indicate that the Size B filters fail completely under Region I tornado conditions. The entire filter medium is removed at a pressure level of approximately $17.25 \mathrm{kPa}$ (2.5 psi). The test results for the Size A filters are not as conclusive. The Pegion I tomado sianlation caused structural failure in two of the four tests completed. These fan lures occurred at pressurization rates lower and higher than that specified for the Region I tornado. We feel that four tests are not a large enough sample to give statistically meaningful results. We would recominend additional testing along with investigation of the failure cechanism. We have suggested several rechanisons in this report, but additional investigations vould be mecessary for conclusive results.

The results of the resistance measurements on the 610- $\times$ 610-mo (24- x 24-in.) filters appear to agree with earlier results obtained for 203- $\times$ 203-L (8- $x$ 8-1n.) filters. Diffusion and momentum exchange may be used to explain the shape of the resistance curves. At relatively low flor rates, the dominant mechanism causing resistance appears to be diffusion, while at higher flow rates, momentum exchange appears to dominate. When momentum exchange doninates, a majority of the flow is probably passing through the folded ends of the fiber mat only, thereby increasing the possibility of inefficient filtration.

Verification of the velocity profices in the simulated pressure loadings was also performed. This analysis indicated that relatively symetric and uniform velocity profiles were obtained.

We have also described parallel activities including progress in construction of the laser and data acquisition systems. Small-scale loading and testing devices were also described. These devices will provide insight into instrumentation requirements and limitations using the 203- x 203-mm $(8-x$ 8-in.) filters and will estatlish testing thethods and procedures that can be used in evaluation of the 610- $\times$ 610-mm (24- x 24-in.) filters.

VII. NEXT WORK PHASE

In the next quarter, the small-scale equipment will be used to do preiliminary aerosol work. Test aerosols will be selected, and the requirements and construction of the aerosol generator will be completed. Calibration, verification tests, and loading procedures will be established. The laser and data acquisition systens will be calibrated and checked against more conventional measuring techniques 
Such as DOP methods, intracavity laser instrumentation, or other postanalysis sampling techniques.

\section{REFERENCES}

1. W. S. Gregory, H. L. Horak, P. R. Smith, and C. Ricketts, "Investigation of HEPA Filters Subjected to Tornado Pressure Pulses," Los Alamos Scientific Laboratcry report LA-NUREG6762-PR (March 1977).
2. E. H. Markee, Jr., and J. G. Beckerley, "Technical Basis for Interis Regional Tormado Criteria," U.S. Atomic Energy Comnissiom, Office of Regulation, Wash 1300 (May 1974).

3. W. S. Gregory, "IIEPA Filter Effectiveness During Tornado Conditions," Los Alamos Scientific Laboratory report LA-5352 (August 1973). 
APPENDIX

EXPERIMENTAL DATA

TABLE A-I

FILTER RESISTANCE TESTS

Filter Number: 41310856

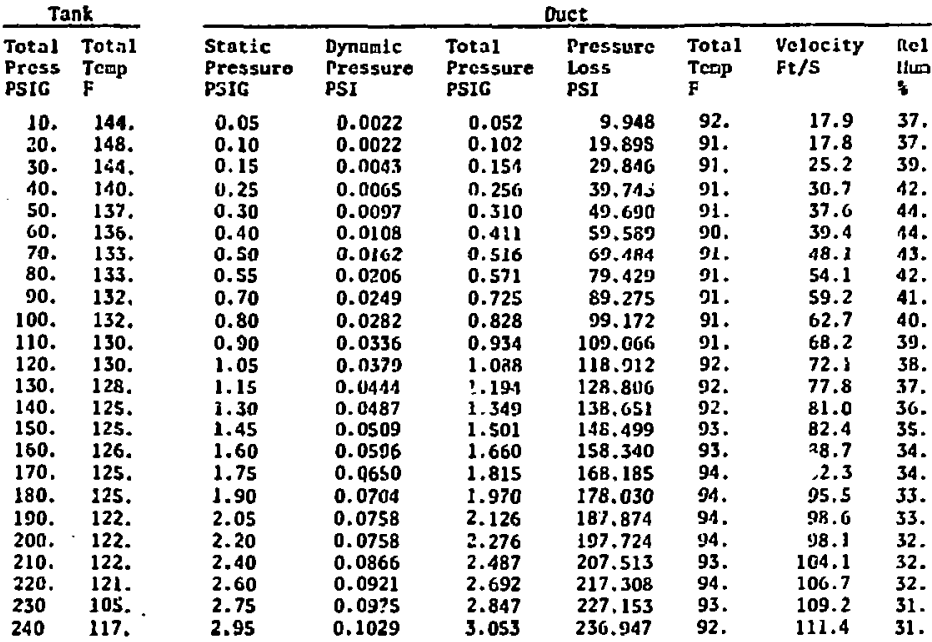

Filter Thickness: $111 / 2 \mathrm{in}$

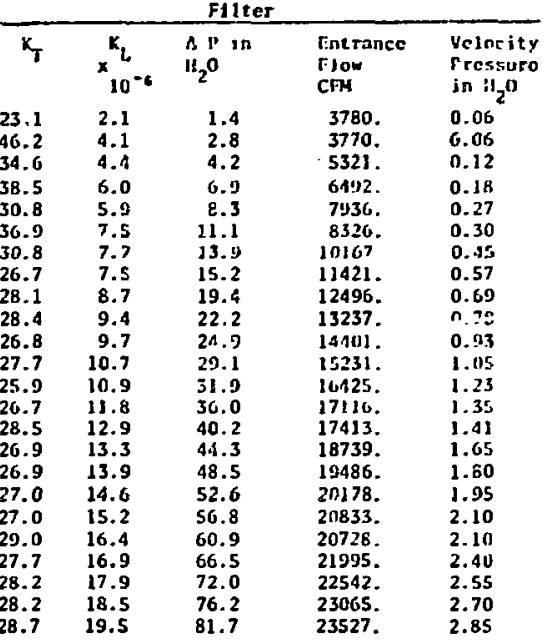

Filter Number: $\mathbf{4 1 3 0 8 0 0 4}$

\begin{tabular}{|c|c|c|c|c|c|c|c|c|}
\hline \multicolumn{2}{|c|}{ Tank } & \multicolumn{7}{|c|}{ Duct } \\
\hline $\begin{array}{l}\text { Total } \\
\text { Press } \\
\text { PS1G }\end{array}$ & $\begin{array}{l}\text { Total } \\
\text { Terap } \\
F\end{array}$ & $\begin{array}{l}\text { Static } \\
\text { Pressure } \\
\text { PSIG }\end{array}$ & $\begin{array}{l}\text { Dynanic } \\
\text { Pressure } \\
\text { PSI }\end{array}$ & $\begin{array}{l}\text { Tota1 } \\
\text { Pressure } \\
\text { PSIG }\end{array}$ & $\begin{array}{l}\text { Pressure } \\
\text { Loss } \\
\text { PSI }\end{array}$ & $\begin{array}{l}\text { Total } \\
\text { Temp } \\
F\end{array}$ & $\begin{array}{l}\text { Velocity } \\
\mathrm{Ft} / \mathrm{s}\end{array}$ & $\begin{array}{l}\text { Rel } \\
\text { Hum } \\
y\end{array}$ \\
\hline $\begin{array}{l}14 . \\
25 . \\
40 . \\
60 . \\
80 . \\
100 . \\
120 . \\
140 . \\
160 . \\
180 . \\
200 . \\
220 . \\
240 . \\
25 j .\end{array}$ & $\begin{array}{l}90 . \\
106 . \\
112 . \\
106 . \\
105 . \\
109 . \\
103 . \\
100 . \\
98 . \\
97 . \\
96 . \\
94 . \\
94 \\
93 .\end{array}$ & $\begin{array}{l}0.10 \\
0.15 \\
0.20 \\
0.35 \\
0.55 \\
0.75 \\
0.95 \\
1.20 \\
1.50 \\
1.75 \\
2.10 \\
2.40 \\
2.80 \\
3.05\end{array}$ & $\begin{array}{l}0.0011 \\
0.0032 \\
0.0065 \\
0.0110 \\
0.0195 \\
0.0271 \\
0.0368 \\
0.0477 \\
0.0574 \\
0.0682 \\
0.0780 \\
0.2499 \\
0.1029 \\
0.1072\end{array}$ & $\begin{array}{l}0.101 \\
0.153 \\
0.206 \\
0.362 \\
0.569 \\
0.777 \\
0.987 \\
1.248 \\
1.557 \\
1.818 \\
2.178 \\
2.490 \\
2.903 \\
3.157\end{array}$ & $\begin{array}{r}13.899 \\
24.847 \\
39.794 \\
59.638 \\
79.430 \\
99.223 \\
119.013 \\
138.752 \\
158.443 \\
178.182 \\
197.822 \\
217.510 \\
237.097 \\
249.815\end{array}$ & $\begin{array}{l}73 . \\
73 . \\
73 . \\
75 . \\
75 . \\
75 . \\
75 . \\
76 . \\
76 . \\
76 . \\
77 . \\
77 . \\
77 . \\
78 .\end{array}$ & $\begin{array}{r}12.4 \\
21.4 \\
30.3 \\
40.8 \\
51.8 \\
60.6 \\
70.2 \\
79.3 \\
86.1 \\
93.0 \\
98.3 \\
104.5 \\
110.4 \\
111.9\end{array}$ & $\begin{array}{l}29 . \\
29 . \\
30 . \\
31 . \\
32 . \\
32 . \\
32 . \\
32 . \\
31 . \\
31 . \\
30 . \\
30 . \\
29 . \\
29 .\end{array}$ \\
\hline
\end{tabular}

Filter Thlekness: 11 1/2 in.

\begin{tabular}{|c|c|c|c|c|}
\hline \multicolumn{5}{|c|}{ Filter } \\
\hline$K_{T}$ & $x_{10}^{R_{L}}$ & $\begin{array}{l}\Delta \mathrm{P} \text { In } \\
\mathrm{H}_{2} \mathrm{O}\end{array}$ & $\begin{array}{l}\text { Entrance } \\
\text { Flow } \\
\text { CHH }\end{array}$ & $\begin{array}{l}\text { Velocity } \\
\text { Pressure } \\
\text { in } \|_{2} \mathrm{O}\end{array}$ \\
\hline $\begin{array}{l}92.3 \\
46.2 \\
30.8 \\
29.4 \\
28.2 \\
27.7 \\
25.8 \\
25.2 \\
26.1 \\
25.6 \\
26.9 \\
26.7 \\
27.2 \\
28.4\end{array}$ & $\begin{array}{r}6.1 \\
5.3 \\
5.0 \\
6.5 \\
8.1 \\
9.4 \\
10.3 \\
11.5 \\
11.2 \\
14.2 \\
16.1 \\
17.4 \\
19.2 \\
20.6\end{array}$ & $\begin{array}{l}2.8 \\
4.2 \\
5.5 \\
9.7 \\
15.2 \\
20.8 \\
26.3 \\
33.2 \\
41.6 \\
48.5 \\
58.2 \\
66.5 \\
77.6 \\
84.5\end{array}$ & $\begin{array}{l}2620 . \\
4530 . \\
6394 . \\
8612 . \\
10946 . \\
12804 . \\
14835 . \\
16738 . \\
18176 . \\
19645 . \\
20770 . \\
22079 . \\
23316 . \\
23632 .\end{array}$ & $\begin{array}{l}0.03 \\
0.09 \\
0.18 \\
0.33 \\
0.54 \\
0.75 \\
1.02 \\
1.32 \\
1.89 \\
1.89 \\
2.16 \\
2.49 \\
2.35 \\
2.97\end{array}$ \\
\hline
\end{tabular}


Filter Nuaber: 41310972

\begin{tabular}{|c|c|c|c|c|c|c|c|c|}
\hline \multicolumn{2}{|c|}{ Tank } & \multicolumn{7}{|c|}{ Duet } \\
\hline $\begin{array}{l}\text { Tota! } \\
\text { Press } \\
\text { PSiG }\end{array}$ & $\begin{array}{l}\text { Total } \\
\text { Tenp } \\
\text { F }\end{array}$ & $\begin{array}{l}\text { Static } \\
\text { Pressure } \\
\text { PSIG }\end{array}$ & $\begin{array}{l}\text { Dymisice } \\
\text { Pressur } \\
\text { PSI }\end{array}$ & $\begin{array}{l}\text { Total } \\
\text { P2 cssure } \\
\text { PSIG }\end{array}$ & $\begin{array}{l}\text { Pressure } \\
\text { Loss } \\
\text { PSI }\end{array}$ & $\begin{array}{l}\text { Toral } \\
\text { Temp } \\
\text { p }\end{array}$ & $\begin{array}{l}\text { Veloeity } \\
\mathrm{Ft} / \mathrm{S}\end{array}$ & \\
\hline $\begin{array}{l}10 . \\
20 . \\
30 . \\
40 . \\
50 . \\
60 . \\
70 . \\
80 . \\
90 . \\
100 . \\
94 . \\
100 . \\
110 . \\
120 . \\
130 \\
140 . \\
150 . \\
160 . \\
170 . \\
180 . \\
190 . \\
200 .\end{array}$ & $\begin{array}{l}120 . \\
125 . \\
134 . \\
130 . \\
126 . \\
114 . \\
116 . \\
116 . \\
117 . \\
116 . \\
85 . \\
84 . \\
8 . \\
86 . \\
86 . \\
86 . \\
86 . \\
88 . \\
88 . \\
88 . \\
88 . \\
88 .\end{array}$ & $\begin{array}{l}0.10 \\
0.20 \\
0.30 \\
0.40 \\
0.50 \\
0.60 \\
0.70 \\
0.85 \\
0.95 \\
1.05 \\
0.95 \\
1.00 \\
1.15 \\
1.30 \\
1.45 \\
1.60 \\
1.75 \\
1.95 \\
2.10 \\
2.30 \\
-2.45 \\
2.65\end{array}$ & $\begin{array}{l}0.0011 \\
0.0022 \\
0.003 ? \\
0.0065 \\
0.0087 \\
0.0130 \\
0.0173 \\
0.0217 \\
0.0227 \\
0.0260 \\
0.0238 \\
0.0271 \\
0.0314 \\
0.0357 \\
0.0412 \\
0.0455 \\
0.0498 \\
0.0552 \\
0.0596 \\
0.0639 \\
0.0682 \\
0.0726\end{array}$ & $\begin{array}{l}0.101 \\
0.202 \\
0.303 \\
0.406 \\
0.509 \\
0.613 \\
0.717 \\
0.872 \\
0.973 \\
1.076 \\
0.974 \\
1.027 \\
1.181 \\
1.336 \\
1.491 \\
1.645 \\
1.800 \\
2.005 \\
2.160 \\
2.364 \\
2.518 \\
2.723\end{array}$ & $\begin{array}{r}9.899 \\
19.798 \\
29.697 \\
39.593 \\
49.491 \\
59.387 \\
69.283 \\
79.128 \\
89.027 \\
98.924 \\
93.026 \\
98.973 \\
108.819 \\
118.654 \\
128.509 \\
138.355 \\
148.200 \\
157.995 \\
167.840 \\
177.636 \\
187.482 \\
197.277\end{array}$ & $\begin{array}{l}90 . \\
90 . \\
90 . \\
90 . \\
90 . \\
90 . \\
90 . \\
90 . \\
91 . \\
92 . \\
69 . \\
70 . \\
71 . \\
71 . \\
72 . \\
72 . \\
72 . \\
73 . \\
73 . \\
74 . \\
75 . \\
75 .\end{array}$ & $\begin{array}{l}12.6 \\
17.8 \\
21.7 \\
30.5 \\
35.1 \\
42.9 \\
49.3 \\
54.8 \\
56.0 \\
59.7 \\
56.2 \\
59.8 \\
64.1 \\
68.1 \\
72.7 \\
76.0 \\
79.2 \\
82.8 \\
85.6 \\
88.1 \\
90.7 \\
93.0\end{array}$ & $\begin{array}{l}47 \\
47 \\
49 \\
50 \\
51 \\
50 \\
50 \\
46 \\
45 \\
43 \\
40 \\
39 \\
38 \\
38 \\
37 \\
37 \\
36 \\
36 \\
36 \\
35 \\
35\end{array}$ \\
\hline
\end{tabular}

Fijece Thickess: $5718 \mathrm{~cm}$

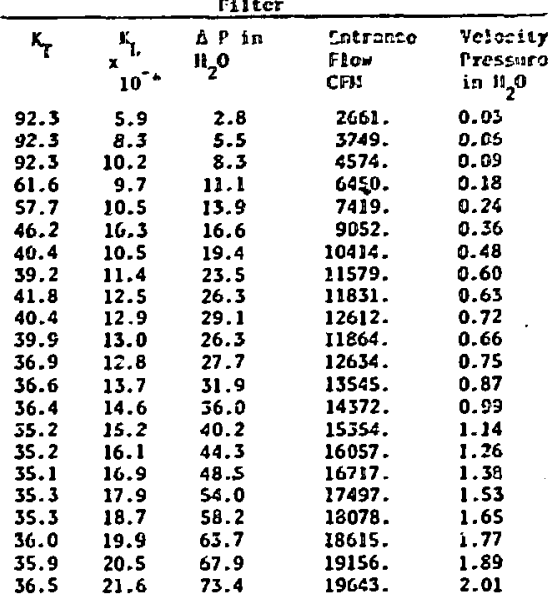

F11ter Number: $\quad 41310977$

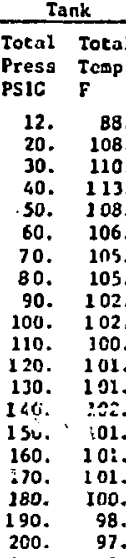

200.98

\section{Duct}

\begin{tabular}{|c|c|c|c|c|c|c|}
\hline $\begin{array}{l}\text { Stat1c } \\
\text { Pressure } \\
\text { PSIC }\end{array}$ & $\begin{array}{l}\text { Dynamic } \\
\text { Pressure } \\
\text { PSI }\end{array}$ & $\begin{array}{l}\text { Total } \\
\text { Pressure } \\
\text { FS1C }\end{array}$ & $\begin{array}{l}\text { Pcessure } \\
\text { Loss } \\
\text { PSI }\end{array}$ & $\begin{array}{l}\text { Total } \\
\text { Tewp } \\
\text { E }\end{array}$ & $\begin{array}{l}\text { Velocity } \\
\mathrm{Ft} / \mathrm{s}\end{array}$ & $\begin{array}{l}\text { Rel } \\
\text { Hua } \\
\text { I }\end{array}$ \\
\hline $\begin{array}{l}0.10 \\
0.20 \\
0.30 \\
0.40 \\
0.45 \\
0.55 \\
0.65 \\
0.80 \\
0.90 \\
1.00 \\
1.10 \\
1.25 \\
1.40 \\
1.55 \\
1.70 \\
1.85 \\
2.00 \\
2.20 \\
2.40 \\
2.55 \\
2.80\end{array}$ & $\begin{array}{l}0.0011 \\
0.0022 \\
0.0043 \\
0.0065 \\
0.0087 \\
0.0119 \\
0.0152 \\
0.0195 \\
0.0238 \\
0.0271 \\
0.0325 \\
0.0379 \\
=.0412 \\
0.0466 \\
0.0520 \\
0.0563 \\
0.0606 \\
0.0661 \\
0.0704 \\
0.0747 \\
0.0791\end{array}$ & $\begin{array}{l}0.101 \\
0.202 \\
0.304 \\
0.406 \\
0.459 \\
0.562 \\
0.665 \\
0.819 \\
0.924 \\
1.027 \\
1.112 \\
1.288 \\
1.441 \\
1.597 \\
1.752 \\
1.906 \\
2.061 \\
2.266 \\
2.470 \\
2.625 \\
2.879\end{array}$ & $\begin{array}{r}11.899 \\
19.798 \\
29.696 \\
39.593 \\
49.541 \\
59.438 \\
69.335 \\
79.180 \\
89.076 \\
98.973 \\
108.868 \\
118.712 \\
128.559 \\
138.403 \\
148.248 \\
158.094 \\
167.919 \\
177.734 \\
187.530 \\
197.375 \\
207.121\end{array}$ & $\begin{array}{l}65 . \\
65 . \\
65 . \\
66 . \\
66 . \\
67 . \\
67 . \\
63 . \\
69 . \\
70 . \\
70 . \\
72 . \\
73 . \\
74 . \\
75 . \\
75 . \\
75 . \\
76 . \\
78 . \\
78 . \\
76 .\end{array}$ & $\begin{array}{l}12.3 \\
17.3 \\
24.4 \\
29.8 \\
34.4 \\
40.2 \\
45.2 \\
51.0 \\
56.3 \\
59.8 \\
65.3 \\
70.3 \\
72.9 \\
77.2 \\
81.2 \\
84.1 \\
86.9 \\
90.1 \\
92.6 \\
94.9 \\
96.7\end{array}$ & $\begin{array}{l}35 . \\
35 . \\
35 . \\
36 . \\
31 . \\
40 . \\
42 . \\
44 . \\
45 . \\
45 . \\
45 . \\
44 . \\
44 . \\
43 . \\
42 . \\
42 . \\
41 . \\
40 . \\
39 . \\
34 . \\
31 .\end{array}$ \\
\hline
\end{tabular}

Filter Thickness: $57 / 8$ in

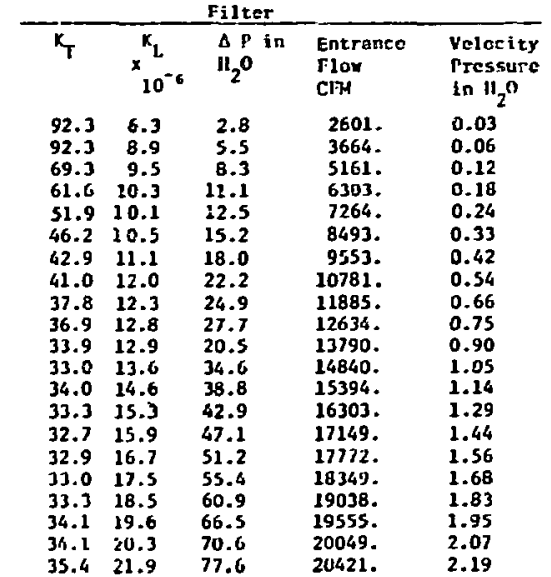

Filter Number: $\$ 1310973$

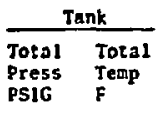

12. 77.

25. 101.

40. 104.

60. 105.

100.100.

120.98.

140.97.

$\begin{aligned} & 160 . \\ & 180 .\end{aligned} 97$.

\section{Duct}

\begin{tabular}{|c|c|c|c|c|c|c|}
\hline $\begin{array}{l}\text { Static } \\
\text { Pressure } \\
\text { PSIC }\end{array}$ & $\begin{array}{l}\text { Dynamic } \\
\text { Pressure } \\
\text { PSI }\end{array}$ & $\begin{array}{l}\text { Total } \\
\text { Pressure } \\
\text { PSIG }\end{array}$ & $\begin{array}{l}\text { Pressure } \\
\text { Loss } \\
\text { PS1 }\end{array}$ & $\begin{array}{l}\text { Total } \\
\text { Temp } \\
F\end{array}$ & $\begin{array}{l}\text { Velocity } \\
\text { Ft/s }\end{array}$ & $\begin{array}{l}\text { Rel } \\
\text { Hurs } \\
t\end{array}$ \\
\hline $\begin{array}{l}0.10 \\
0.20 \\
0.35 \\
0.50 \\
0.70 \\
0.90 \\
1.15 \\
1.45 \\
1.75 \\
2.10 \\
2.50\end{array}$ & $\begin{array}{l}0.0011 \\
0.0032 \\
0.0054 \\
0.0119 \\
0.0173 \\
0.0249 \\
0.0336 \\
0.0422 \\
0.0617 \\
0.0606 \\
0.0715\end{array}$ & $\begin{array}{l}0.101 \\
0.203 \\
0.355 \\
0.512 \\
0.717 \\
0.925 \\
1.184 \\
1.492 \\
1.803 \\
2.161 \\
2.571\end{array}$ & $\begin{array}{r}11.899 \\
24.797 \\
39.645 \\
59.488 \\
79.283 \\
99.075 \\
118.816 \\
138.508 \\
158.188 \\
177.839 \\
197.429\end{array}$ & $\begin{array}{l}72 . \\
71 . \\
71 . \\
72 . \\
73 . \\
74 . \\
75 . \\
75 . \\
74 . \\
74 . \\
75 .\end{array}$ & $\begin{array}{l}12.4 \\
21.4 \\
37.4 \\
40.5 \\
48.5 \\
57.8 \\
66.5 \\
73.8 \\
80.2 \\
86.4 \\
92.7\end{array}$ & $\begin{array}{l}34 . \\
34 . \\
35 . \\
37 . \\
38 . \\
38 . \\
38 . \\
37 . \\
36 . \\
35 . \\
35 .\end{array}$ \\
\hline
\end{tabular}

Filter Thleknoss: $57 / 8 \mathrm{im}$.

\begin{tabular}{|c|c|c|c|c|}
\hline \multicolumn{4}{|c|}{ Filter } & \multirow[b]{2}{*}{$\begin{array}{l}\text { Velocity } \\
\text { f'ressure } \\
\text { in } \mathrm{I}_{2} \mathrm{O}\end{array}$} \\
\hline$k_{T}$ & $\times_{10^{-}}^{x_{1}}$ & $\begin{array}{l}\Delta P \text { in } \\
\|_{2}{ }^{\circ}\end{array}$ & $\begin{array}{l}\text { Entrance } \\
\text { flow } \\
\text { cris }\end{array}$ & \\
\hline $\begin{array}{l}92.3 \\
61.6 \\
64.6 \\
42.0 \\
40.4 \\
36.1 \\
3.3 \\
34.3 \\
28.3 \\
34.6 \\
35.0\end{array}$ & $\begin{array}{r}6.2 \\
7.2 \\
9.8 \\
9.4 \\
11.0 \\
11.5 \\
13.1 \\
14.9 \\
15.1 \\
18.5 \\
20.5\end{array}$ & $\begin{array}{r}2.8 \\
5.5 \\
9.7 \\
13.9 \\
19.4 \\
24.9 \\
31.9 \\
40.2 \\
48.5 \\
58.2 \\
69.3\end{array}$ & $\begin{array}{l}2618 . \\
4513 . \\
5793 . \\
2551 . \\
10245 . \\
12203 . \\
14051 . \\
15593 . \\
16920 . \\
18257 . \\
19575 .\end{array}$ & $\begin{array}{l}0.03 \\
0.09 \\
0.15 \\
0.33 \\
0.48 \\
0.69 \\
0.93 \\
1.17 \\
1.41 \\
1.68 \\
1.98\end{array}$ \\
\hline
\end{tabular}

